\title{
The Relationship between Organizational Health and Student Achievement in High Poverty Schools
}

\author{
Rosalinda Hernandez, Ph.D. \\ The University of Texas Rio Grande Valley \\ Edinburg, Texas USA \\ Roberto Zamora, Ph.D. \\ The University of Texas Rio Grande Valley \\ Edinburg, Texas USA
}

\begin{abstract}
The purpose of this study was to examine the relationship between organizational health and student achievement of economically disadvantaged students in a large school district along the Texas-Mexico border that serves $99 \%$ Hispanic students; districtwide approximately $95 \%$ of the students are economically disadvantaged. All schools in the district are Title I schools and enroll 78\%- 100\% economically disadvantaged students. About forty-eight percent (48.3\%) of students served are English Language Learners. Student achievement was determined using the State of Texas Assessment of Academic Readiness (STAAR) and organizational health was determined using an Organizational Health Inventory that measures the ten dimensions of organization-al health posited by Matthew Miles and operationalized by Marvin Fairman and Associates. The strength of the relationship was determined by using the Pearson correlation coefficient. The findings indicate that there is a positive relationship between student achievement in high poverty Hispanic schools and organizational health. The strongest relationship exists with the dimensions of goal focus, problem solving adequacy, and cohesiveness. Student achievement increases as the dimension of goal focus increases.
\end{abstract}

Keywords: organizational health; organizational structures; dimensions; student achievement.

\section{Introduction}

Transparency of student achievement data to the public has been the norm for schools across the nation. This norm has placed undeniable pressure on school leaders and teachers to address the needs of an increasingly diverse population. Though schools have cycled through decades of focused school 
improvement strategies, test results continue to reveal gaps in achievement between economically disadvantaged and non-economically disadvantaged students (Murphy, 2009; Reardon, 2013; Anderson, 2017). Furthermore, policymakers continue to exert their influence on school leaders to create and maintain effective schools so that all students master the required standards and to foster a learning environment in which achievement gaps between diverse groups of students are closed (Thernstrom, 2003). This study focused on the school learning environment to determine if organizational health is an essential alterable variable to increasing student achievement of economically disadvantaged students.

Schools seldom examine the health of the organization to determine its relationship on student achievement. School leaders and teachers primarily focus on implementing pedagogical practices in the areas of curriculum, instruction, and assessment to increase achievement test results. Little or no consideration on student achievement data, as it relates to how existing organizational structures, processes, staff relationships, and academic emphasis, affect the results attained (Goddard, Sweetland, \& Hoy, 2000).

Therefore, is it possible that schools and its stakeholders have relied on student achievement data as the only measureable method for determining the success of a school without considering organizational health as a critical factor to improving student achievement? Could it be that school leaders lack knowledge about the importance of organizational health on improving student achievement especially the achievement of economically disadvantaged students? With increasing student achievement standards and the increasing number of economically disadvantaged students served by public schools across the country, the researchers deemed it imperative to examine the relationship between organizational health and student achievement in high poverty schools.

\section{Theoretical Framework}

Demands from various stakeholders for schools to improve student achievement and to close the achievement gap between economically disadvantaged and non-economically disadvantaged students compel district and school leaders to deliberately examine achievement results and assess how organizational structures, processes, and practices implemented may have contributed to results attained. Persuaded by these realities and a deeply felt professional moral obligation, the researchers examined the original work of social scientist Matthew Miles in Planned Change and Organizational Health: Figure and Ground (1965). In this paper, Miles stated that "any particular planned change is deeply conditioned by the state of the system in which it takes place" (p. 11) and admonished "that successful efforts at planned change must take as a primary target the improvement of organizational health" (pp. 11-12). Miles characterized a healthy organization as one that "not only survives in its environment, but continues to cope adequately over the long haul, and continuously develops and extends its surviving and coping abilities" (p. 17).

Miles identified and described ten dimensions of organizational health. Goal focus, communication adequacy, and optimal power equalization were task oriented. Resource utilization, cohesiveness, and morale were maintenance oriented. Innovativeness, autonomy, adaptation and problem solving adequacy 
dealt with growth and changefulness. Essentially, Miles brought to the forefront the need for educators to understand the powerful influence of organizational structures, processes and practices on the effectiveness of schools. Miles also proposed interventions to diagnose and improve the organizational health of schools. Fairman, Holmes, Hardage, and Lucas (1979) operationally defined the ten dimensions of organizational health proposed by Miles (1981). Subsequently, Fairman and McLean (2014) created the Sustained Systemic Success Model (Figure 1) to assist school leaders improve organizational health, leadership effectiveness and student achievement.

To conduct this study, researchers utilized the Sustained Systemic Success Model created by Fairman and McLean (2014). The Sustained Systemic Success Model TM illustrates the essential elements for attaining excellence in student achievement that emerges from the implementation of effective leadership practices founded on a principle-centered conceptual infrastructure. Implementing this systemic school improvement model, built on a principlecentered theoretical foundation, offers educators at all organizational levels a framework upon which to align structures, systems, processes, and strategies with high performance expectations necessary to achieve the school's vision, mission and goals.

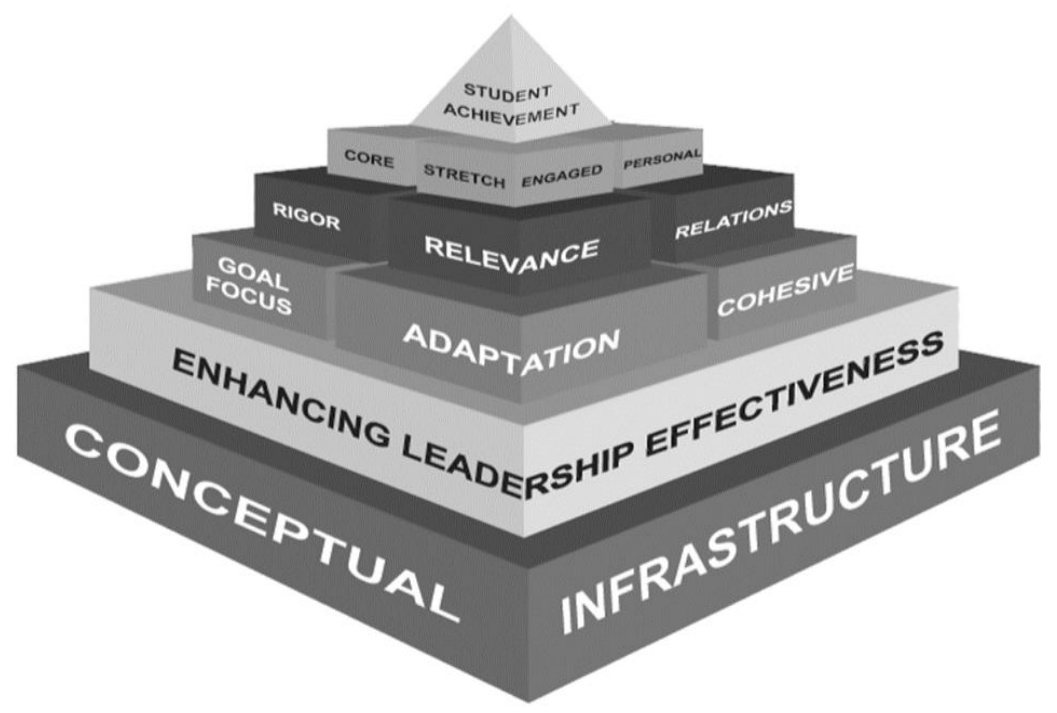

Figure 1. Sustained Systemic Success Model ${ }^{\mathrm{TM}}$, Enhancing Leadership Effectiveness, Fairman and McLean (2014).

This conceptual model, depicted as a staircase pyramid, consists of six interdependent levels that result in sustained systemic success. The first level, the conceptual infrastructure, emphasizes the importance of the organization's guiding principles, beliefs, mission, vision and goals. Together, these provide a strong sense of purpose and direction for the organization and serve as a decision making screen for all school improvement initiatives and ongoing dayto-day operations. The second level stresses the importance of leadership and represents an unwavering commitment to enhance leadership effectiveness in order to improve student achievement. Situational leadership concepts posited by Hersey and Blanchard (1988) serve as the basis for leadership development. 
The ten dimensions of organizational health make up the third level. The dimensions displayed - Goal Focus, Adaptation and Cohesiveness - represent the three dimensions demonstrated by Fairman and McLean (2014) which have the strongest relationship to student achievement. The fourth level focuses on curricula required to ensure that rigorous and relevant instruction provided promote student engagement and learning of higher order thinking skills. Noting the personal curriculum asserts the importance of capitalizing on strengths that students possess and bring to the learning process. The fifth level highlights the importance of providing rigorous and relevant instruction infused with higher order thinking skills and $21^{\text {st }}$ century learning experiences. It also emphasizes the importance of creating a teaching and learning environment marked by relationships that foster school connectedness and a strong sense of belonging for adults and students. The apex of the pyramid, the sixth level, accentuates the overall purpose of the model - to promote student achievement for all students.

\section{Dimensions of Organizational Health}

An explanation of the ten dimensions of organizational health operationalized by Fairman and McLean (2011) follows. Goal focus is the capacity of an individual, team, or organization to clearly understand, accept, support, internalize and advocate for the organization's goals. They also emphasize the importance of setting reasonable and achievable goals that will provide direction for the organization. Communication adequacy is realized when members of the organization receive sufficient and timely information without needing to exert undue effort to acquire it. Communication adequacy implies that communication emanating from the organization or from its external environment flows across the organization with minimal or no distortion. Optimal power equalization refers to the sharing of power or influence within the organization by formal positional leaders. The amount of influence or power the leader grants an individual is contingent upon the individual's competence and commitment to perform a given task. Thus, power or influence may depend on the task to be completed. Notable about this dimension is the term optimal. This implies the need for leaders to ensure that the power shared is relatively equitable. In essence, it calls attention to the need for leaders to recognize that sharing too little or too much power may be detrimental to the health and effectiveness of the organization. Resource utilization reflects the extent to which individuals believe the organization appropriately utilizes their skills. In a healthy organization, the phrase "best fit" results when leaders align individuals' skills and dispositions to their position's roles and responsibilities. When this occurs, individuals will perform their duties with a minimal sense of strain and will feel better about their job and the organization. Cohesiveness indicates the extent to which individuals, groups, or organizations have a clear sense of identity and sense of belonging. Individuals feel connected to members of their team and to the organization and teams work interdependently. Individuals want to be members of their teams. They want to influence others and are willing to allow others to influence them. Team members demonstrate high levels of collaboration and hold each other accountable, individually and collectively, to do what they agree to do. Morale refers to job satisfaction and the 
degree that individuals believe their leaders trust and value them. The status of other organizational health dimensions impact morale. Autonomy means that individuals, teams, or organizations, have the freedom to make decisions. Autonomy encourages teachers to take ownership and accept responsibility for improving student achievement. The level of autonomy granted depends on the competency and commitment levels of individuals and teams. Adaptation assesses the extent to which individuals and teams, with minimal stress, are able to adapt and cope with the demands for change from the external environment. Problem solving adequacy focuses on structures and processes implemented by an organization to solve problems with minimal effort. The expectation is that when problems arise, they are resolved in a timely manner and remain solved.

\section{The Economically Disadvantaged Child}

In spite of school improvement efforts implemented after adoption of the No Child Left Behind (NCLB) in the 2011 legislation (NCLB, 2011) the achievement gap, in reading and mathematics, between economically disadvantaged and non-economically disadvantaged students continue to exist (Blank, 2011). School administrators grapple with the need to improve students' academic performance and to attain the highest marks in federal and state accountability systems. School improvement efforts schools have primarily focused on changing structural arrangements, time on task, and pedagogy to improve student achievement. The need for schools to change and the need for schools to improve the achievement of Hispanic and economically disadvantaged students are indisputable (TEA, 2014; CCSSO, 2011; Hemphill, 2011). Adding to this discourse, Murphy (2009) states that existing achievement gaps "damage the economic and social fabric of society" (p. 11). As a result of his extensive study encompassing five decades on the relationship between achievement and family income, Reardon exhorts " if we do not find ways to reduce the growing inequality in education outcomes - between the rich and poor - schools will no longer be the great equalizer we want them to be" (Reardon, 2013, p. 10).

The need to increase achievement of economically disadvantaged students at the national level emerged in the mid-1960s with the introduction of the Elementary and Secondary Education Act (ESEA). This Act provided districts formula grants to implement supplementary programs and services to assist underperforming, economically disadvantaged students. In 2002, the No Child Left Behind bill passed with a major focus on closing the achievement gap between the rich and poor and between white and students of color. To measure progress made towards closing the achievement gaps, NCLB included an accountability system that required states to assess students annually in reading and math in grades three through eight and to disaggregate and report results " for students by poverty levels, race, ethnicities, disabilities, and limited English proficiencies" (USDE, 2002, p. 9).

The Every Student Succeeds Act (ESSA) signed into law by President Obama in 2015 continued to include accountability measures that report disaggregated academic achievement data including achievement of economically disadvantaged and non-economically disadvantaged students. U. S. Secretary of Education John B. King referred to assessment requirements as 
"critical tool(s) that can help educators, parents, and policymakers promote educational equity by highlighting achievement gaps, especially for our traditionally underserved students" (USDE, 2015, p. 1).

Disparities in achievement gaps persist in spite of efforts at the local, state and national level. Environmental and school factors affect the achievement of students of poverty. School factors include the quality of the curriculum, rigor of instruction, quality and experience of teachers, school safety and school climate (Reardon, 2013). Baker, Farrie, and Sclarra (2016) declare that certain structural factors such as school funding, allocation of resources and class size impact student achievement. School climate and culture influence student achievement (DuFour \& Eaker, 1998; Barth, 2002). Sarason (1996) adds credence to the importance of school culture by declaring that structural changes made to improve schools without addressing the culture of schools have been unsuccessful. Hoy et al (1990; 2012) further support the concept that culture, climate, and organizational health of the school affects student achievement.

\section{What is Organizational Health?}

Argyris (1958) introduced the concept of organizational health in an article titled "The Organization: What Makes It Healthy" and asserted that to determine the health of an organization one must examine the inside of the organization and not simply be satisfied with the outward picture. Furthermore, Argyris noted that management is not the sole determinant of organizational health and that "the very nature of the organization and of managerial controls 'if practiced correctly' makes them equally crucial factors" (p. 107). Behavioral scientist Matthew Miles (1965) introduced the concept of organizational health and its application to public schools at a seminar entitled Change Processes in Public Schools. In his seminal paper on the organizational health of schools, Miles wrote that a healthy organization "not only survives in its environment, but continues to cope adequately over the long haul, and continuously develops and extends its surviving and coping abilities" (p. 17). He defined organizational health as "the school's ability not only to function effectively, but to develop and grow into a more fully functioning system" (pp. 11-12). Miles' ten dimensions of organizational health represent characteristics and processes that work interactively within the system to influence the health of the organization and the results the organization produces.

Matthew Miles' research has served as the basis for the work and research conducted nationally by Marvin Fairman over the last four decades. Fairman's (2011) work and research have confirmed the importance of organizational health and its impact on student achievement. Studies on the impact of organizational health on student achievement further substantiate this positive relationship (Alqarni, 2016; Brosnahan, 2011; Macneil, Prater, \& Busch, 2009). Nevertheless, school improvement strategies to increase student achievement seldom include the improvement of organizational health. Befittingly, schools have concentrated on implementing initiatives that target changing instruction, curriculum and assessment practices. This study proposes to provide insights about organizational functions that will assist educators increase student achievement of students enrolled in high poverty, linguistically diverse schools. Moreover, it affirms the relationship between organizational 
health and the achievement of students (3-11 grades), based on the English language arts and mathematics state assessment, who are enrolled in high poverty Hispanic schools in South Texas.

\section{Methodology and Research Design}

The purpose of this quantitative study was to determine the relationship between the ten dimensions and total organizational health and student achievement of economically disadvantaged students in high poverty Title I schools. The researchers used a survey method to collect teacher perceptions, and, the results of the State of Texas Assessment of Academic Readiness (STAAR) acquired from the school district's Research and Evaluation Office. The research questions were as follows:

1. Is there a relationship between student achievement in reading, writing and mathematics combined, hereafter referred to as Student Performance Index (SPI), and the ten dimensions of organizational health and total organizational health?

2. Is there a relationship between student achievement (SPI) and the percent of economically disadvantaged students enrolled in school?

3. Is there a relationship between student achievement (SPI), percent of economically disadvantaged students enrolled per campus and organizational health by dimension and total organizational health?

4. Is there a relationship between student achievement (SPI), percent of economically disadvantaged students enrolled per campus, and the dimension of goal focus?

\section{Research Design}

The researchers used the Organizational Health Instrument (OHI) survey developed by Fairman, Holmes, Hardage, and Lucas (1979). Instrument development entailed a rigorous three-year, three-phase process to determine its validity and reliability. OHI results measure perceptions of total workgroups such as departments and schools. Results indicate "group mean ratings of the items within each dimension. Interpretation of the scores of individual workgroup members is not intended. Therefore, the measures of reliability of the OHI scales are based on group data to reflect the actual conditions of using the OHI" (Johnstone, 1988, p. 5).

The Pearson correlation coefficient statistical method assesses the strength of relationships between student achievement results in reading, writing and mathematics (SPI) combined of economically disadvantaged students and organizational health by dimensions and as total organizational health. The strength of the relationship was determined using a 2-tailed $t$ distribution at the .05 level of significance. The research hypotheses were:

$\mathrm{H}_{1} .1$ - There is a positive relationship between student achievement in reading, writing and mathematics combined, hereafter referred to as Student Performance Index (SPI), and the ten dimensions of organizational health and total organizational health.

$\mathrm{H}_{0.1}$ - There is no relationship between student achievement in reading, writing and mathematics combined, hereafter referred to as Student Performance Index 
(SPI), and the ten dimensions of organizational health and total organizational health.

$\mathrm{H}_{1} .2$ - There is a negative relationship between student achievement (SPI) and the percent of economically disadvantaged students enrolled in school.

$\mathrm{H}_{0} .2$ - There is a no relationship between student achievement (SPI) and the percent of economically disadvantaged students enrolled in school.

$\mathrm{H}_{1} .3$ - There is a positive relationship between student achievement (SPI), percent of economically disadvantaged students enrolled per campus, and organizational health by dimension and total organizational health.

$\mathrm{H}_{0} .3$ - There is no relationship between student achievement (SPI), percent of economically disadvantaged students enrolled per campus, and organizational health by dimension and total organizational health.

$\mathrm{H}_{1} .4$ - There is a positive relationship between student achievement (SPI), percent of economically disadvantaged students enrolled per campus, and the dimension of goal focus.

$\mathrm{H}_{0} .4$ - There is a no relationship between student achievement (SPI), percent of economically disadvantaged students enrolled per campus, and the dimension of goal focus.

\section{Data Sources and Collection Procedures}

Based on Texas Education Agency data (2014), the participating elementary, middle and high schools in this study were 35 Title I schools with approximately 95\% economically disadvantaged student enrollment (TEA, 2014). The composite demographics for the district are as follows: $99.6 \%$ Hispanic, 50.5\%, English Language Learners (ELLs) and $79.9 \%$ at risk. The primary language of all ELLs is Spanish (TEA).

Data utilized for this study reflect the percent of students that met the state's Phase-in Satisfactory Standards in reading and mathematics, and writing in elementary schools and end of course exams in English Language Arts I, English Language Arts II, and Algebra I in high school (TEA, 2014). Researchers calculated the Student Performance Index (SPI). The SPI for elementary and middle schools represent the average percent of students who met the state's Phase-in Satisfactory standards in reading, writing and mathematics. The SPI in high schools represent the average percent of students who met the state's Phase-in Satisfactory standards in ELA I, ELA II and Algebra I. The district's Research and Evaluation Office provided the data pertaining to the percent of economically disadvantaged students enrolled at each campus. These data represent the percent of students eligible to receive free or reduced lunch.

The organizational health instrument $(\mathrm{OHI})$ developed by Fairman et al (1979) served as the data collection instrument for this study. This survey measured the quality of the school's environment and "the more subtle and complex internal systemic dynamics that improve productivity" (Fairman, 2014, p. 8). The survey consisted of eighty items; eight items for each of the ten dimensions randomly placed throughout the organizational health instrument. Reversal items are included. Respondents rated each item on a Likert scale continuum as: (1) Strongly Disagree, (2) Disagree, (3) Undecided, (4) Strongly Agree or (5) Strongly Agree (Johnstone, 1988).

Survey participants included teachers from all the 35 schools. 
Individuals completed the survey during a scheduled meeting of approximately 20 minutes. Data collected were confidential thus diminishing and eliminating the possibility of compromising results due to "social desirability" bias (Phillips \& Clancy, 1972). An analysis of the survey results, by dimension and total organization health, occurred for each campus.

\section{Findings}

Table 1 displays the percentile scores for each of the ten dimensions and the total organizational health $(\mathrm{OH})$ score, the student performance index (SPI), and the percent of students receiving free and reduced lunch (Eco-D). The last two rows exhibit the correlation coefficients for each of the dimensions of $\mathrm{OH}$ and the SPI. At the bottom of Table 1, recorded below the correlation coefficient, is the level of statistical significance. The SPI and economically disadvantaged data for each school appear in Table 1. The numbers on Table 1 represent percentiles. The column titled S, displays in upper case letters secondary schools and in lower case letters elementary schools.

Table 1. Correlation between Student Performance and Dimensions of Organizational Health and Economically Disadvantaged Students.

\begin{tabular}{|c|c|c|c|c|c|c|c|c|c|c|c|c|c|}
\hline$s$ & GF & COM & OPE & RES & $\mathrm{COH}$ & MOR & $\mathbb{I N N}$ & AUT & ADA & PSA & TOH & SPI & ED \\
\hline $\mathrm{a}$ & 56 & 43 & 48 & 49 & 36 & 30 & 49 & 16 & 27 & 24 & 38 & 57 & 96 \\
\hline A & 10 & 6 & 9 & 7 & 3 & 12 & 7 & 13 & 7 & 6 & 8 & 62 & 100 \\
\hline b & 94 & 75 & 81 & 87 & 81 & 83 & 86 & 56 & 80 & 78 & 80 & 61 & 94 \\
\hline B & 80 & 59 & 43 & 61 & 34 & 54 & 34 & 32 & 53 & 67 & 52 & 69 & 98 \\
\hline c & 83 & 48 & 46 & 71 & 60 & 48 & 45 & 21 & 63 & 37 & 52 & 70 & 97 \\
\hline C & 99 & 92 & 92 & 95 & 89 & 92 & 88 & 71 & 84 & 93 & 89 & 72 & 95 \\
\hline $\mathrm{d}$ & 82 & 64 & 60 & 66 & 62 & 67 & 53 & 19 & 45 & 63 & 58 & 79 & 96 \\
\hline e & 42 & 33 & 19 & 34 & 29 & 33 & 26 & 9 & 18 & 28 & 27 & 63 & 95 \\
\hline f & 32 & 16 & 37 & 15 & 11 & 21 & 23 & 13 & 13 & 13 & 19 & 59 & 94 \\
\hline F & 41 & 35 & 35 & 37 & 38 & 41 & 37 & 19 & 37 & 33 & 35 & 60 & 97 \\
\hline G & 64 & 42 & 43 & 39 & 17 & 28 & 40 & 28 & 48 & 35 & 38 & 58 & 98 \\
\hline$g$ & 80 & 70 & 51 & 70 & 43 & 59 & 48 & 19 & 51 & 62 & 55 & 72 & 98 \\
\hline $\mathrm{H}$ & 49 & 25 & 34 & 27 & 20 & 13 & 28 & 16 & 18 & 21 & 25 & 59 & 99 \\
\hline h & 65 & 71 & 62 & 54 & 52 & 61 & 55 & 30 & 50 & 57 & 56 & 68 & 96 \\
\hline i & 96 & 90 & 90 & 91 & 80 & 87 & 90 & 70 & 84 & 79 & 86 & 73 & 91 \\
\hline J & 78 & 69 & 70 & 74 & 54 & 71 & 64 & 46 & 54 & 52 & 63 & 59 & 99 \\
\hline $\mathrm{j}$ & 95 & 91 & 90 & 95 & 84 & 95 & 91 & 84 & 88 & 84 & 90 & 72 & 88 \\
\hline $\mathrm{K}$ & 42 & 45 & 39 & 43 & 48 & 48 & 38 & 19 & 28 & 33 & 38 & 65 & 96 \\
\hline k & 85 & 54 & 62 & 62 & 72 & 68 & 59 & 41 & 56 & 53 & 61 & 85 & 78 \\
\hline L & 70 & 76 & 63 & 45 & 59 & 65 & 59 & 32 & 32 & 34 & 54 & 69 & 93 \\
\hline 1 & 66 & 49 & 59 & 59 & 54 & 61 & 46 & 36 & 42 & 56 & 53 & 72 & 89 \\
\hline $\mathrm{m}$ & 53 & 51 & 44 & 52 & 42 & 48 & 45 & 27 & 40 & 41 & 44 & 63 & 98 \\
\hline $\mathrm{M}$ & 97 & 86 & 88 & 86 & 75 & 85 & 92 & 49 & 78 & 75 & 81 & 73 & 95 \\
\hline $\mathrm{n}$ & 51 & 42 & 29 & 41 & 25 & 38 & 31 & 14 & 21 & 31 & 32 & 58 & 98 \\
\hline$\circ$ & 69 & 58 & 26 & 48 & 72 & 58 & 48 & 11 & 55 & 46 & 49 & 59 & 89 \\
\hline $\mathrm{p}$ & 36 & 26 & 33 & 12 & 15 & 24 & 13 & 10 & 14 & 12 & 20 & 67 & 91 \\
\hline$q$ & 69 & 49 & 34 & 43 & 19 & 50 & 29 & 16 & 17 & 33 & 36 & 70 & 84 \\
\hline $\mathcal{Q}$ & 99 & 99 & 99 & 99 & 99 & 99 & 99 & 99 & 99 & 99 & 99 & 90 & 98 \\
\hline I & 90 & 75 & 69 & 76 & 72 & 84 & 87 & 71 & 74 & 71 & 77 & 65 & 96 \\
\hline R & 59 & 47 & 29 & 38 & 31 & 42 & 20 & 19 & 26 & 37 & 35 & 74 & 92 \\
\hline$s$ & 88 & 74 & 67 & 81 & 68 & 76 & 77 & 48 & 61 & 65 & 70 & 76 & 96 \\
\hline$t$ & 85 & 30 & 28 & 62 & 46 & 45 & 41 & 15 & 36 & 51 & 44 & 80 & 90 \\
\hline $\mathrm{u}$ & 93 & 83 & 86 & 62 & 67 & 87 & 77 & 61 & 66 & 72 & 76 & 69 & 93 \\
\hline $\mathrm{v}$ & 77 & 53 & 53 & 71 & 64 & 64 & 56 & 51 & 66 & 55 & 61 & 83 & 81 \\
\hline$w$ & 89 & 58 & 49 & 73 & 54 & 61 & 43 & 47 & 81 & 56 & 61 & 70 & 98 \\
\hline$r$ & 570 & .439 & .428 & .534 & .543 & .539 & .397 & .466 & .469 & .558 & .523 & -.472 & \\
\hline$a$ & .001 & .05 & 0.05 & 0.01 & 0.01 & 0.01 & 0.05 & 0.01 & 0.01 & .001 & 0.01 & .01 & \\
\hline
\end{tabular}

$r$ - Correlation Coefficient $\alpha$-Level of Statistical Significance GF - Goal Focus; COM - Communication Adequacy; OPE - Optimal Power Equalization; RES - Resource Utilization; COH- Cohesiveness; Mor - Morale; INN - Innovativeness; ADA Adaptation; AUT Autonomy; PSA Problem Solving Adequacy; T OH - Total 
Organizational Health; SPI\% - \% Student Performance Index;

ED\% - \% Economically Disadvantaged

Goal focus and problem solving adequacy were statistically significant at the .001 level of significance; resource utilization, cohesiveness, morale, autonomy, and adaptation were significant at the .01 level; and, communication adequacy, optimal power equalization, and innovation were significant at the .05 level. By contrast, the relationship between SPI and Eco-D produced a negative relationship that was statistically significant at .01 level of significance.

\section{Relationship between Student Achievement (Student Performance Index) and Dimensions of Organizational Health.}

Table 2 depicts the relationship between student achievement (SPI) and organizational health ranked by strength of relationship. Results support the research hypothesis $\mathrm{H}_{1} 1$ that states that there is a positive relationship between student achievement (SPI) and each of the 10 dimensions of organizational health and the Total Organizational Health score. Results reject $\mathrm{H}_{0 .} 1$ that states there is no relationship between student achievement (SPI) and each of the 10 dimensions of organizational health and the Total Organizational Health score. The strongest relationships are evident between student achievement and the $\mathrm{OH}$ dimensions of goal focus and problem solving adequacy. These relationships are significant at the .001 level. The relationships were statistically significant at the .01 level for five dimensions: cohesiveness, morale, resource utilization, adaptation and autonomy. Statistically significant at the .05 level were the dimensions of communications, optimal power equalization, and communication adequacy. Overall, the relationship between student achievement and Total Organizational Health was significant at the .01 level.

Table 2. Relationship between Student Achievement (SPI) \& Organizational Health Ranked by Strength of Relationship

\begin{tabular}{|r|l|l|l|l|}
\hline Rank & Dimension & $\boldsymbol{r}$ & $\mathbf{\alpha}$ & $\begin{array}{l}\text { Strength of } \\
\text { Relationship }\end{array}$ \\
\hline 1. & Goal Focus & .5698 & .001 & Strong \\
\hline 2. & $\begin{array}{l}\text { Problem Solving } \\
\text { Adequacy }\end{array}$ & .5580 & .001 & Strong \\
\hline 3. & Cohesiveness & .5427 & .01 & Strong \\
\hline 4. & Morale & .5394 & .01 & Strong \\
\hline 5. & Resource Utilization & .5336 & .01 & Strong \\
\hline 6. & Adaptation & .4694 & .01 & Moderate \\
\hline 7. & Autonomy & .4661 & .01 & Moderate \\
\hline 8. & Communications & .4391 & .05 & Moderate \\
\hline 9. & $\begin{array}{l}\text { Optimal Power } \\
\text { Equalization }\end{array}$ & .4281 & .05 & Moderate \\
\hline 10. & Innovativeness & .3967 & .05 & Moderate \\
\hline & Total OH & .5231 & .01 & Strong \\
\hline
\end{tabular}

$\mathbf{r}=$ Pearson correlation coefficient; $\alpha=$ level of statistical significance 


\section{Relationship between Student Achievement (SPI) and Percent of Economically Disadvantaged Students Enrolled per Campus}

The scatter plot in Figure 2 displays the relationship between Eco-D and the SPI. The SPI scores are on the vertical axis and the Eco-D are on the horizontal axis. The correlation coefficient as reported in Figure 1 is - .4726 and is represented by the diagonal regression line that shows which as the percentage of Eco-D student increases there is a corresponding decrease in the SPI scores. The " $X$ " represents the district's average scores for the SPI and Eco-D students with scores of 69 and 94, respectively.

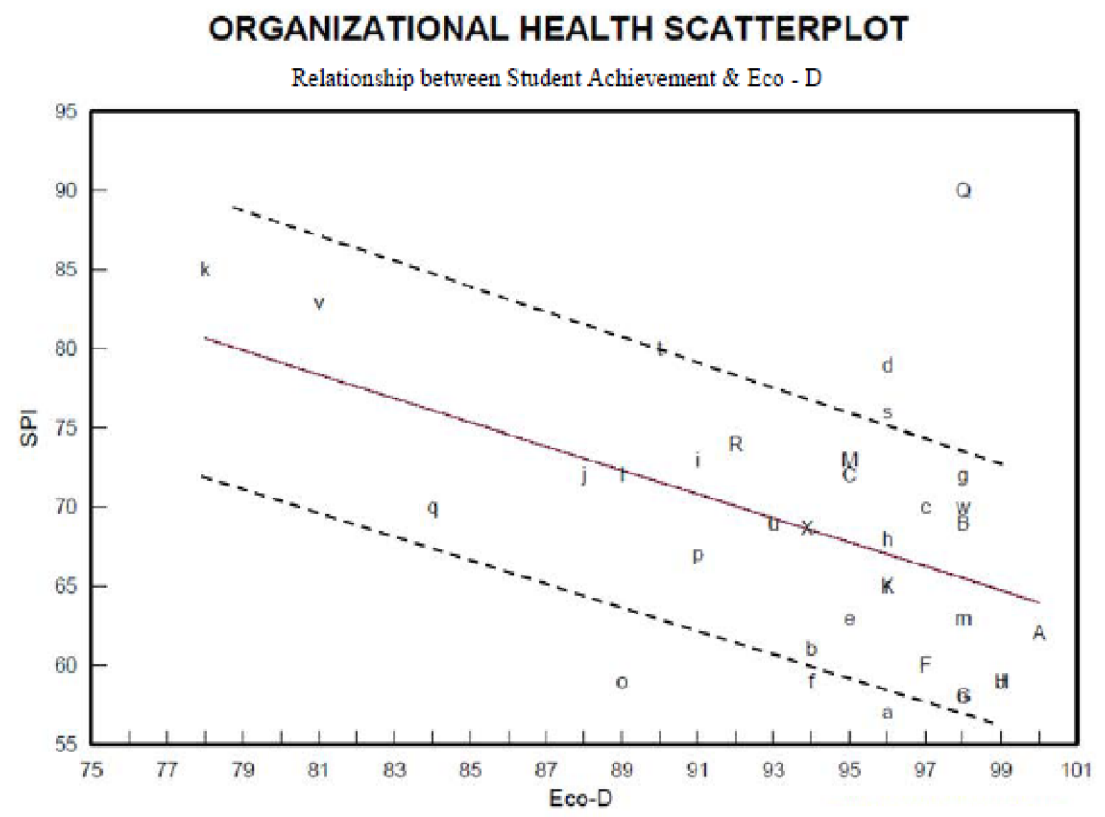

Figure 2. Relationship between student performance and percent economically disadvantaged students enrolled per campus. $\mathrm{r}=-.4726 ; \mathrm{a}=.01$.

Fifteen schools that are performing above the regression line are performing higher than expected. Twenty schools are below the regression line and are performing less well than expected. The organizational health scores for those schools above and below the regression line appear in Table 3 below. 
Table 3. Organizational Health Data for Schools Above and Below the Regression Line

\begin{tabular}{|c|c|c|c|c|c|c|c|c|c|c|}
\hline $\mathrm{S}$ & GF & $\mathrm{COM}$ & OPE & RES & $\mathrm{COH}$ & MOR & INN & AUT & $\mathrm{ADA}$ & PSA \\
\hline B & $80 \%$ & $59 \%$ & $43 \%$ & $61 \%$ & $34 \%$ & $54 \%$ & $34 \%$ & $32 \%$ & $53 \%$ & $67 \%$ \\
\hline C & $99 \%$ & $92 \%$ & $92 \%$ & $95 \%$ & $89 \%$ & $92 \%$ & $88 \%$ & $71 \%$ & $84 \%$ & $93 \%$ \\
\hline c & $83 \%$ & $48 \%$ & $46 \%$ & $71 \%$ & $60 \%$ & $48 \%$ & $45 \%$ & $21 \%$ & $63 \%$ & $37 \%$ \\
\hline d & $82 \%$ & $64 \%$ & $60 \%$ & $66 \%$ & $62 \%$ & $67 \%$ & $53 \%$ & $19 \%$ & $45 \%$ & $63 \%$ \\
\hline 8 & $80 \%$ & $70 \%$ & $51 \%$ & $70 \%$ & $43 \%$ & $59 \%$ & $48 \%$ & $19 \%$ & $51 \%$ & $62 \%$ \\
\hline $\mathrm{h}$ & $65 \%$ & $71 \%$ & $62 \%$ & $54 \%$ & $52 \%$ & $61 \%$ & $55 \%$ & $30 \%$ & $50 \%$ & $57 \%$ \\
\hline $\mathrm{i}$ & $96 \%$ & $90 \%$ & $90 \%$ & $91 \%$ & $80 \%$ & $87 \%$ & $90 \%$ & $70 \%$ & $84 \%$ & $79 \%$ \\
\hline $\mathrm{k}$ & $85 \%$ & $54 \%$ & $62 \%$ & $62 \%$ & $72 \%$ & $68 \%$ & $59 \%$ & $41 \%$ & $56 \%$ & $53 \%$ \\
\hline M & $97 \%$ & $86 \%$ & $88 \%$ & $86 \%$ & $75 \%$ & $85 \%$ & $92 \%$ & $49 \%$ & $78 \%$ & $75 \%$ \\
\hline$Q$ & $99 \%$ & $99 \%$ & $99 \%$ & $99 \%$ & $99 \%$ & $99 \%$ & $99 \%$ & $99 \%$ & $99 \%$ & $99 \%$ \\
\hline $\mathbf{R}$ & $59 \%$ & $47 \%$ & $29 \%$ & $38 \%$ & $31 \%$ & $42 \%$ & $20 \%$ & $19 \%$ & $26 \%$ & $37 \%$ \\
\hline 5 & $88 \%$ & $74 \%$ & $67 \%$ & $81 \%$ & $68 \%$ & $76 \%$ & $77 \%$ & $48 \%$ & $61 \%$ & $65 \%$ \\
\hline$t$ & $85 \%$ & $30 \%$ & $28 \%$ & $62 \%$ & $46 \%$ & $45 \%$ & $41 \%$ & $15 \%$ & $36 \%$ & $51 \%$ \\
\hline $\mathrm{v}$ & $77 \%$ & $53 \%$ & $53 \%$ & $71 \%$ & $64 \%$ & $64 \%$ & $56 \%$ & $51 \%$ & $66 \%$ & $55 \%$ \\
\hline$w$ & $89 \%$ & $58 \%$ & $49 \%$ & $73 \%$ & $54 \%$ & $61 \%$ & $43 \%$ & $47 \%$ & $81 \%$ & $56 \%$ \\
\hline $\begin{array}{l}\text { Above } \\
\text { R Line }\end{array}$ & $84 \%$ & $66 \%$ & $61 \%$ & $72 \%$ & $62 \%$ & $67 \%$ & $60 \%$ & $42 \%$ & $62 \%$ & $63 \%$ \\
\hline A & $10 \%$ & $6 \%$ & $9 \%$ & $7 \%$ & $3 \%$ & $12 \%$ & $7 \%$ & $13 \%$ & $7 \%$ & $6 \%$ \\
\hline a & $56 \%$ & $43 \%$ & $48 \%$ & $49 \%$ & $36 \%$ & $30 \%$ & $49 \%$ & $16 \%$ & $27 \%$ & $24 \%$ \\
\hline b & $94 \%$ & $75 \%$ & $81 \%$ & $87 \%$ & $81 \%$ & $83 \%$ & $86 \%$ & $56 \%$ & $80 \%$ & $78 \%$ \\
\hline e & $42 \%$ & $33 \%$ & $19 \%$ & $34 \%$ & $29 \%$ & $33 \%$ & $26 \%$ & $9 \%$ & $18 \%$ & $28 \%$ \\
\hline F & $41 \%$ & $35 \%$ & $35 \%$ & $37 \%$ & $38 \%$ & $41 \%$ & $37 \%$ & $19 \%$ & $37 \%$ & $33 \%$ \\
\hline f & $32 \%$ & $16 \%$ & $37 \%$ & $15 \%$ & $11 \%$ & $21 \%$ & $23 \%$ & $13 \%$ & $13 \%$ & $13 \%$ \\
\hline G & $64 \%$ & $42 \%$ & $43 \%$ & $39 \%$ & $17 \%$ & $28 \%$ & $40 \%$ & $28 \%$ & $48 \%$ & $35 \%$ \\
\hline $\mathrm{H}$ & $49 \%$ & $25 \%$ & $34 \%$ & $27 \%$ & $20 \%$ & $13 \%$ & $28 \%$ & $16 \%$ & $18 \%$ & $21 \%$ \\
\hline $\mathrm{j}$ & $95 \%$ & $91 \%$ & $90 \%$ & $95 \%$ & $84 \%$ & $95 \%$ & $91 \%$ & $84 \%$ & $88 \%$ & $84 \%$ \\
\hline $\mathrm{J}$ & $78 \%$ & $69 \%$ & $70 \%$ & $74 \%$ & $54 \%$ & $71 \%$ & $64 \%$ & $46 \%$ & $54 \%$ & $52 \%$ \\
\hline $\mathrm{K}$ & $42 \%$ & $45 \%$ & $39 \%$ & $43 \%$ & $48 \%$ & $48 \%$ & $38 \%$ & $19 \%$ & $28 \%$ & $33 \%$ \\
\hline I & $66 \%$ & $49 \%$ & $59 \%$ & $59 \%$ & $54 \%$ & $61 \%$ & $46 \%$ & $36 \%$ & $42 \%$ & $56 \%$ \\
\hline L & $70 \%$ & $76 \%$ & $63 \%$ & $45 \%$ & $59 \%$ & $65 \%$ & $59 \%$ & $32 \%$ & $32 \%$ & $34 \%$ \\
\hline $\mathrm{m}$ & $53 \%$ & $51 \%$ & $44 \%$ & $52 \%$ & $42 \%$ & $48 \%$ & $45 \%$ & $27 \%$ & $40 \%$ & $41 \%$ \\
\hline $\mathrm{n}$ & $51 \%$ & $42 \%$ & $29 \%$ & $41 \%$ & $25 \%$ & $38 \%$ & $31 \%$ & $14 \%$ & $21 \%$ & $31 \%$ \\
\hline 0 & $69 \%$ & $58 \%$ & $26 \%$ & $48 \%$ & $72 \%$ & $58 \%$ & $48 \%$ & $11 \%$ & $55 \%$ & $46 \%$ \\
\hline $\mathrm{p}$ & $36 \%$ & $26 \%$ & $33 \%$ & $12 \%$ & $15 \%$ & $24 \%$ & $13 \%$ & $10 \%$ & $14 \%$ & $12 \%$ \\
\hline$q$ & $69 \%$ & $49 \%$ & $34 \%$ & $43 \%$ & $19 \%$ & $50 \%$ & $29 \%$ & $16 \%$ & $17 \%$ & $33 \%$ \\
\hline I & $90 \%$ & $75 \%$ & $69 \%$ & $76 \%$ & $72 \%$ & $84 \%$ & $87 \%$ & $71 \%$ & $74 \%$ & $71 \%$ \\
\hline $\mathrm{u}$ & $93 \%$ & $83 \%$ & $86 \%$ & $62 \%$ & $67 \%$ & $87 \%$ & $77 \%$ & $61 \%$ & $66 \%$ & $72 \%$ \\
\hline $\begin{array}{c}\text { Below R } \\
\text { Line }\end{array}$ & 6096 & $49 \%$ & $47 \%$ & $47 \%$ & $42 \%$ & $49 \%$ & $46 \%$ & $30 \%$ & $39 \%$ & $40 \%$ \\
\hline
\end{tabular}

Figure 3 displays the composite organizational health profile for schools above and below the regression line. All ten dimensions were higher for those schools above the regression line with a composite difference of 19 percentile points. The greatest difference was resource utilization with 25 point and the least difference was autonomy with a difference of 12 percentile points. 


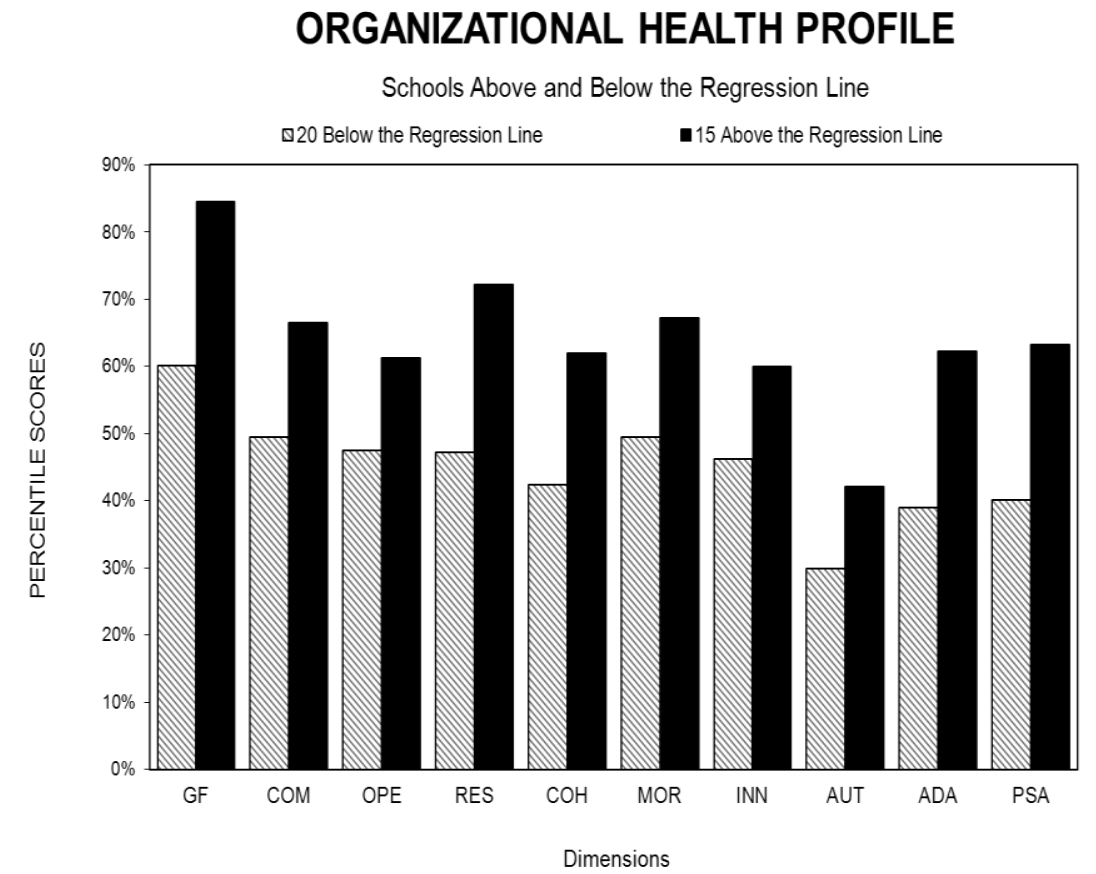

Figure 3. Organizational Health profile for schools above and below the regression line

The researchers also examined the achievement "bookends," that is, those schools in the top 10 percent above the regression line, and those schools in the bottom 10 percent below the regression line. Figure 4 displays a dashed line below and parallel to the regression line to identify those schools with an SPI in the bottom 10\%. Those schools below the dashed line in Figure 4 are "a," " $\mathrm{f}$," and "o." Similarly, the dashed line above and parallel to the regression line identify those schools with an SPI in the top $10 \%$. Schools above the dashed line in Figure 3 are schools as " $\mathrm{d}$ ", "Q", and "s." Identifying the top $10 \%$ and bottom $10 \%$ further allows an organizational health comparative analysis of four groups of schools:

- The three schools above the top dashed line;

- The twelve schools between the regression line and the top dashed line;

- The seventeen schools between the regression line and the bottom dashed line; and

- The three schools below the bottom dashed line. 


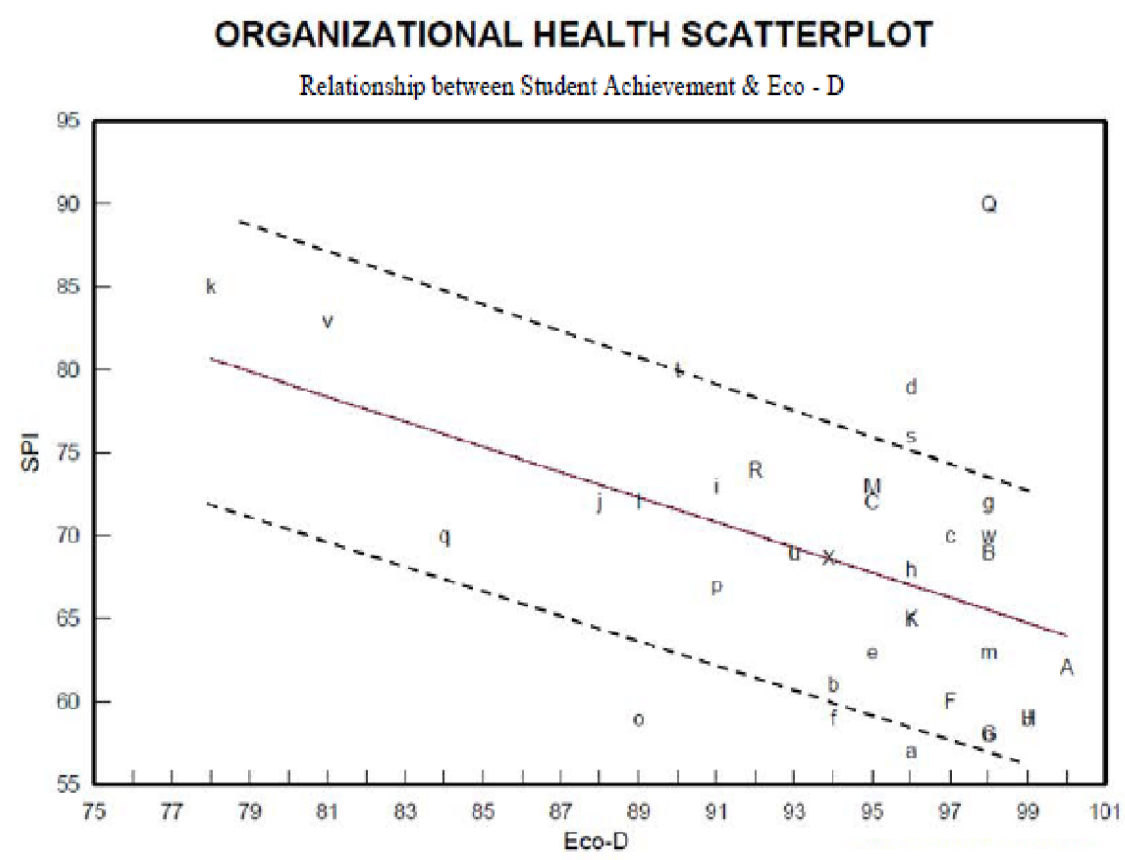

Figure 4. Relationship between student performance (SPI) and economically disadvantaged students enrolled per campus.

The composite organizational health scores for these four distinct groups of schools appear in Table 4. Results indicate that the average organizational health scores for all ten $\mathrm{OH}$ dimensions of the four distinct groups of schools are the highest for schools above the top dashed line and are the lowest for schools below the bottom dashed line. The highest $\mathrm{OH}$ dimension composite score for all groups of schools was goal focus. The lowest $\mathrm{OH}$ dimension for all groups of schools was autonomy. 
Table 4. Composite Organizational Health Data for the Four Groups of Schools

\begin{tabular}{|c|c|c|c|c|c|c|c|c|c|c|}
\hline $\mathrm{S}$ & GF & $\mathrm{COM}$ & OPE & RES & $\mathrm{COH}$ & MOR & INN & AUT & ADA & PSA \\
\hline $\bar{d}$ & $82 \%$ & $64 \%$ & $60 \%$ & $66 \%$ & $62 \%$ & $67 \%$ & $53 \%$ & $19 \%$ & $45 \%$ & $63 \%$ \\
\hline$Q$ & $99 \%$ & $99 \%$ & $99 \%$ & $99 \%$ & $99 \%$ & $99 \%$ & $99 \%$ & $99 \%$ & $99 \%$ & $99 \%$ \\
\hline s & $88 \%$ & $74 \%$ & $67 \%$ & $81 \%$ & $68 \%$ & $76 \%$ & $77 \%$ & $48 \%$ & $61 \%$ & $65 \%$ \\
\hline AVG & $90 \%$ & $790 \%$ & $75 \%$ & 820 & $760 \%$ & 810 & $770 \%$ & $55 \%$ & $69 \%$ & $76 \%$ \\
\hline B & $80 \%$ & $59 \%$ & $43 \%$ & $61 \%$ & $34 \%$ & $54 \%$ & $34 \%$ & $32 \%$ & $53 \%$ & $67 \%$ \\
\hline C & $99 \%$ & $92 \%$ & $92 \%$ & $95 \%$ & $89 \%$ & $92 \%$ & $88 \%$ & $71 \%$ & $84 \%$ & $93 \%$ \\
\hline c & $83 \%$ & $48 \%$ & $46 \%$ & $71 \%$ & $60 \%$ & $48 \%$ & $45 \%$ & $21 \%$ & $63 \%$ & $37 \%$ \\
\hline$g$ & $80 \%$ & $70 \%$ & $51 \%$ & $70 \%$ & $43 \%$ & $59 \%$ & $48 \%$ & $19 \%$ & $51 \%$ & $62 \%$ \\
\hline h & $65 \%$ & $71 \%$ & $62 \%$ & $54 \%$ & $52 \%$ & $61 \%$ & $55 \%$ & $30 \%$ & $50 \%$ & $57 \%$ \\
\hline i & $96 \%$ & $90 \%$ & $90 \%$ & $91 \%$ & $80 \%$ & $87 \%$ & $90 \%$ & $70 \%$ & $84 \%$ & $79 \%$ \\
\hline k & $85 \%$ & $54 \%$ & $62 \%$ & $62 \%$ & $72 \%$ & $68 \%$ & $59 \%$ & $41 \%$ & $56 \%$ & $53 \%$ \\
\hline M & $97 \%$ & $86 \%$ & $88 \%$ & $86 \%$ & $75 \%$ & $85 \%$ & $92 \%$ & $49 \%$ & $78 \%$ & $75 \%$ \\
\hline R & $59 \%$ & $47 \%$ & $29 \%$ & $38 \%$ & $31 \%$ & $42 \%$ & $20 \%$ & $19 \%$ & $26 \%$ & $37 \%$ \\
\hline$t$ & $85 \%$ & $30 \%$ & $28 \%$ & $62 \%$ & $46 \%$ & $45 \%$ & $41 \%$ & $15 \%$ & $36 \%$ & $51 \%$ \\
\hline $\mathrm{v}$ & $77 \%$ & $53 \%$ & $53 \%$ & $71 \%$ & $64 \%$ & $64 \%$ & $56 \%$ & $51 \%$ & $66 \%$ & $55 \%$ \\
\hline w & $89 \%$ & $58 \%$ & $49 \%$ & $73 \%$ & $54 \%$ & $61 \%$ & $43 \%$ & $47 \%$ & $81 \%$ & $56 \%$ \\
\hline AVG & $83 \%$ & $63 \%$ & $58 \%$ & $70 \%$ & $580 \%$ & 640 & $56 \%$ & $390 \%$ & $61 \%$ & $60 \%$ \\
\hline A & $10 \%$ & $6 \%$ & $9 \%$ & $7 \%$ & $3 \%$ & $12 \%$ & $7 \%$ & $13 \%$ & $7 \%$ & $6 \%$ \\
\hline b & $94 \%$ & $75 \%$ & $81 \%$ & $87 \%$ & $81 \%$ & $83 \%$ & $86 \%$ & $56 \%$ & $80 \%$ & $78 \%$ \\
\hline e & $42 \%$ & $33 \%$ & $19 \%$ & $34 \%$ & $29 \%$ & $33 \%$ & $26 \%$ & $9 \%$ & $18 \%$ & $28 \%$ \\
\hline F & $41 \%$ & $35 \%$ & $35 \%$ & $37 \%$ & $38 \%$ & $41 \%$ & $37 \%$ & $19 \%$ & $37 \%$ & $33 \%$ \\
\hline G & $64 \%$ & $42 \%$ & $43 \%$ & $39 \%$ & $17 \%$ & $28 \%$ & $40 \%$ & $28 \%$ & $48 \%$ & $35 \%$ \\
\hline $\mathrm{H}$ & $49 \%$ & $25 \%$ & $34 \%$ & $27 \%$ & $20 \%$ & $13 \%$ & $28 \%$ & $16 \%$ & $18 \%$ & $21 \%$ \\
\hline j & $95 \%$ & $91 \%$ & $90 \%$ & $95 \%$ & $84 \%$ & $95 \%$ & $91 \%$ & $84 \%$ & $88 \%$ & $84 \%$ \\
\hline $\mathrm{J}$ & $78 \%$ & $69 \%$ & $70 \%$ & $74 \%$ & $54 \%$ & $71 \%$ & $64 \%$ & $46 \%$ & $54 \%$ & $52 \%$ \\
\hline K & $42 \%$ & $45 \%$ & $39 \%$ & $43 \%$ & $48 \%$ & $48 \%$ & $38 \%$ & $19 \%$ & $28 \%$ & $33 \%$ \\
\hline 1 & $66 \%$ & $49 \%$ & $59 \%$ & $59 \%$ & $54 \%$ & $61 \%$ & $46 \%$ & $36 \%$ & $42 \%$ & $56 \%$ \\
\hline L & $70 \%$ & $76 \%$ & $63 \%$ & $45 \%$ & $59 \%$ & $65 \%$ & $59 \%$ & $32 \%$ & $32 \%$ & $34 \%$ \\
\hline $\mathrm{m}$ & $53 \%$ & $51 \%$ & $44 \%$ & $52 \%$ & $42 \%$ & $48 \%$ & $45 \%$ & $27 \%$ & $40 \%$ & $41 \%$ \\
\hline $\mathbf{n}$ & $51 \%$ & $42 \%$ & $29 \%$ & $41 \%$ & $25 \%$ & $38 \%$ & $31 \%$ & $14 \%$ & $21 \%$ & $31 \%$ \\
\hline p & $36 \%$ & $26 \%$ & $33 \%$ & $12 \%$ & $15 \%$ & $24 \%$ & $13 \%$ & $10 \%$ & $14 \%$ & $12 \%$ \\
\hline$q$ & $69 \%$ & $49 \%$ & $34 \%$ & $43 \%$ & $19 \%$ & $50 \%$ & $29 \%$ & $16 \%$ & $17 \%$ & $33 \%$ \\
\hline $\mathbf{r}$ & $90 \%$ & $75 \%$ & $69 \%$ & $76 \%$ & $72 \%$ & $84 \%$ & $87 \%$ & $71 \%$ & $74 \%$ & $71 \%$ \\
\hline $\mathrm{u}$ & $93 \%$ & $83 \%$ & $86 \%$ & $62 \%$ & $67 \%$ & $87 \%$ & $77 \%$ & $61 \%$ & $66 \%$ & $72 \%$ \\
\hline AVG & $61 \%$ & $51 \%$ & $49 \%$ & $490 \%$ & $43 \%$ & $52 \%$ & $47 \%$ & $33 \%$ & $40 \%$ & $42 \%$ \\
\hline a & $56 \%$ & $43 \%$ & $48 \%$ & $49 \%$ & $36 \%$ & $30 \%$ & $49 \%$ & $16 \%$ & $27 \%$ & $24 \%$ \\
\hline f & $32 \%$ & $16 \%$ & $37 \%$ & $15 \%$ & $11 \%$ & $21 \%$ & $23 \%$ & $13 \%$ & $13 \%$ & $13 \%$ \\
\hline 0 & $69 \%$ & $58 \%$ & $26 \%$ & $48 \%$ & $72 \%$ & $58 \%$ & $48 \%$ & $1 \%$ & $55 \%$ & $46 \%$ \\
\hline AVG & $520 \%$ & $39 \%$ & $37 \%$ & $37 \%$ & $400 \%$ & $37 \%$ & $40 \%$ & $13 \%$ & $31 \%$ & $28 \%$ \\
\hline
\end{tabular}

Figure 5 graphically displays organizational health scores by dimensions for each of these four groups. The black bar displays the organizational health, by dimension, of the three schools with an SPI above the top dashed line. The organizational health, by dimension, of the 12 schools with an SPI that appears between the regression line and the top dashed line appear as gray bars. Back slash pattern bars represent the organizational health, by dimension, of the 17 schools with an SPI between the regression line and the bottom dashed line. The organizational health, by dimension, of the three schools with an SPI below the bottom dashed line appear in forward slash pattern bars. The "stair step" pattern displayed indicates that the organizational health for these four groups of schools is very different on all ten dimensions. These results also indicate schools that have higher health scores also have higher student performance even when percent of economically disadvantaged students is similar to or higher than other schools. 


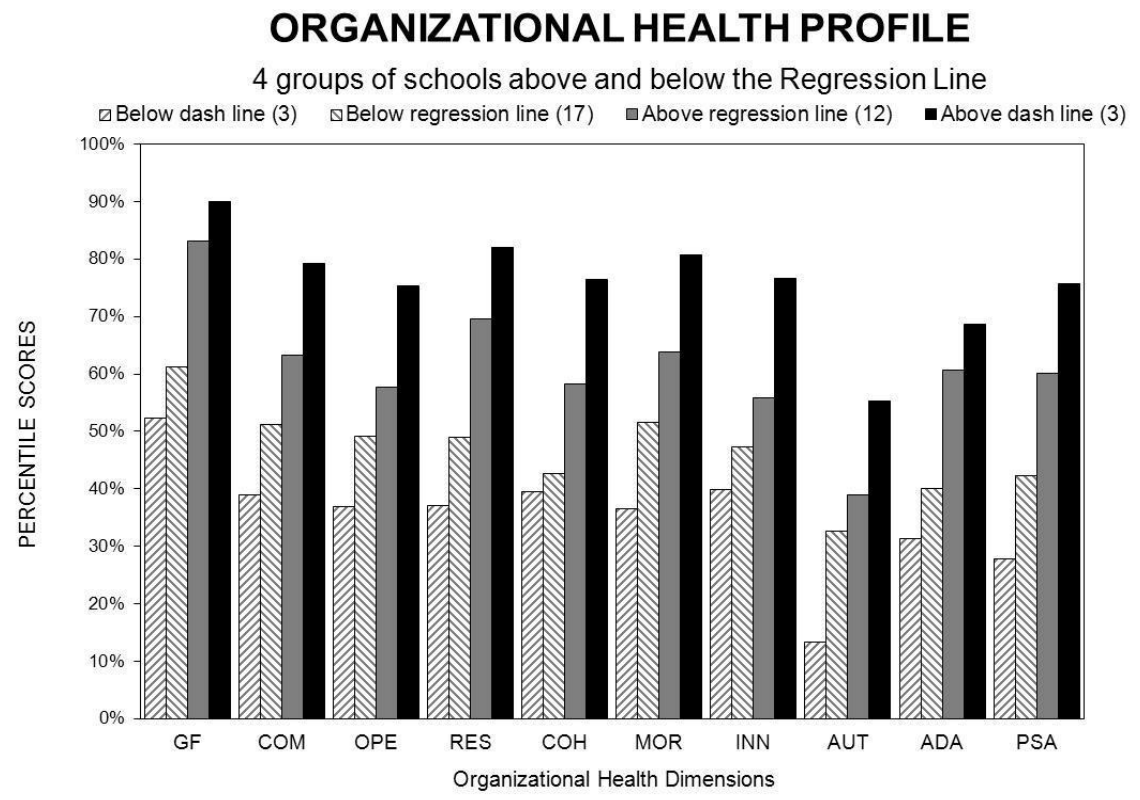

Figure 5. Organizational Health Profile for the four groups of schools above and below the regression line

As previously documented, the relationship between student performance and economically disadvantaged students produced a negative relationship of-.4726 that was statistically significant at the .01 level. However, the negative relationship between socio-economic status and student performance as depicted in Figure 5 is not a cause and effect relationship. The 15 schools above the regression line in Figure 6 are demonstrating that the level of organizational health eclipses the economic disadvantage barrier. The composite organizational health profile for each of the four groups of schools provides empirical evidence that the organizational health of schools has a positive impact on student achievement. It also suggests that the organizational health of schools in this district has a greater impact on student achievement than the percent of economically disadvantaged students enrolled in the schools.

The data revealed that the dimension of Goal Focus has the highest composite score for all four groups of schools. Therefore, the researchers compared student achievement, the dependent variable, with the independent variable, the dimension of goal focus. Results of the analysis displayed in Figure 6 indicate that as the level of goal focus increases, a corresponding increase in the levels of student achievement occurs. 


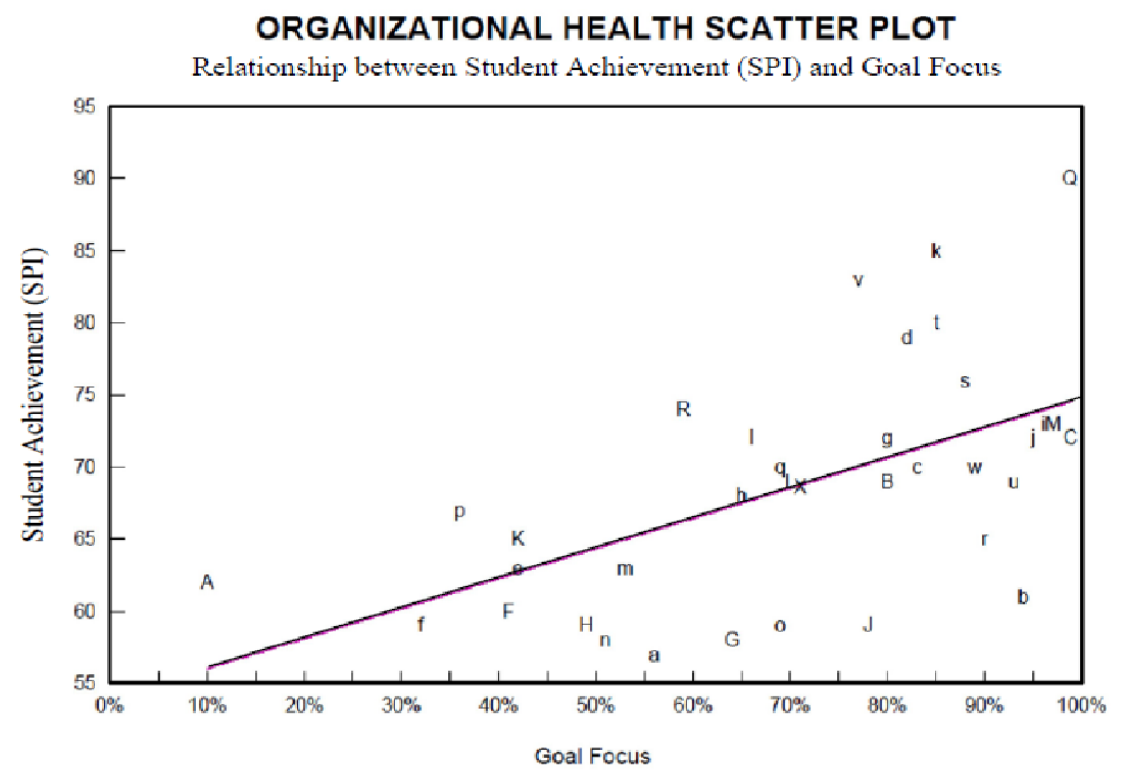

Figure 6. Relationship between student achievement (SPI) Goal Focus. $r=.5698 ; \mathrm{a}=.0001$

Although it was not within the scope of this study, it is important to indicate that schools whose level of goal focus and student achievement are higher than statistically predicted warrant further analysis to discover the specific structures, systems, strategies, and leadership practices that may be contributing to attainment of higher organizational health scores and higher student achievement. The researchers recommend that other researchers replicate this study to determine the power of organizational health in improving student achievement.

\section{Implications}

Results of this study reveal that a positive relationship exists between student achievement and the ten dimensions of organizational health and total organizational health in this high poverty, Hispanic Title I district. These findings augment the work of other researchers and scholars (Hoy 1990, 1997, 2012; MacNeil, 2009; Roney, 2011; Brosnahan, 2011). Results call attention to the need for district and school leaders to incorporate organizational health diagnostic and improvement strategies to their school improvement efforts. Attempts to increase student achievement must be coupled with deliberate strategies to increase the overall health of the organization. The greater the challenges a school faces to improve student achievement, the greater the need is to improve organizational health. Increasing organizational health requires change in current structures, practices, processes and relationships. Because district and school leaders are in the best position to influence what happens in schools that impact the organizational health of the school, leaders must consider the following questions. when seeking to improve organizational health(Fairman \& McLean, 2011, 2014) 
1. What structures, including policies, practices and procedures, do schools have in place that contribute to the organizational health of the schools?

2. What changes need to be considered to improve the organizational health of schools?

3. What are district and school leaders doing or not doing that influence the organizational health of the schools?

4. What changes must occur to improve the organizational health of schools?

5. What are district and school staff doing or not doing that influence the health of a school?

6. What must members of the organization do differently to improve the organizational health of schools?

7. What processes, such as decision making, problem solving and communication, do we have in place that are contributing to the organizational health of the schools?

8. What processes, such as decision making, problem solving and communication do schools have in place that contribute to the health of an organization?

Data pertaining to the relationship between student achievement and the ten dimensions of organizational health indicate that a positive relationship exists between student achievement and all ten dimensions and total organizational health. The strongest relationship exists between student achievement and the dimensions of goal focus, problem solving adequacy, and cohesiveness.

Attention to Goal Focus fosters acceptance, support and advocacy for goals developed to address student achievement priorities. Because results reveal that Goal Focus is the dimension that has the strongest relationship to student achievement, it is important that school leaders engage faculty and other stakeholders in the goal development process to foster the support and advocacy required for goal attainment. Leaders must provide supports needed by faculty to attain established goals. These results further substantiate the importance of academic emphasis pointed out by Goddard, Sweetland, and Hoy (2000).

To enhance Problem-Solving Adequacy, leaders must institute structures and processes to ensure concerns and issues are addressed and resolved on a timely basis. Problem solving will be more effective when decisions are made at the closest point of implementation by those who have the competence and commitment to resolve identified problems (Fairman, 2011). Leaders must provide clear decision making structures such as organizational charts, position roles and responsibilities, and a problem-solving process. The overarching intent of the problem solving structures and processes should be to promote implementation of win/win rather than win/lose or lose/lose decision making.

Leaders can strengthen Cohesiveness by facilitating the creation of a trusting environment and structures where members can feel safe to have open and honest discussions pertaining to student achievement. Within these environments, team members should plan proactively, analyze causes for achievement gaps, and collaboratively determine win-win strategies for improving student achievement. Team members should also hold themselves and each other accountable for implementing improvement strategies. 
A negative relationship exists between student achievement (SPI) and the percent of economically disadvantaged students enrolled per campus. As the percent of economically disadvantaged students enrolled per campus increased, there was a corresponding decrease in student achievement (SPI). This is consistent with other studies that have found that socioeconomic status (SES) is one of the most important factors that determines student achievement. In summarizing the impact of poverty on student achievement, Blazer and Romanick (2009) wrote:

Research indicates that low income students tend to have significantly lower levels of academic achievement than their more affluent peers. The number of disadvantaged students attending a school also affects student performance. Students at all income levels have been found to have lower levels of achievement when they attend schools with high poverty concentrations ( $\mathrm{p}$. $1)$.

In this study, researchers delved deeper to determine the relationship between organizational health, percent of economically disadvantaged students enrolled in the school, and student achievement. Results indicate that a positive relationship exists between the ten dimensions of organizational health and total organization health. Likewise, the results indicate that student achievement is higher in schools with higher organizational health scores. While the strength of the relationships varies between the ten dimensions and student achievement, it is important to note that schools with higher student achievement have higher organizational health scores than lower performing schools across all ten dimensions and total organizational health score. The organizational health and student performance data in this study validate the power of organizational health in addressing the diverse learning needs of economically disadvantaged students.

\section{References}

Alqarni, S.A.Y., (2016). Linking organizational health in Jeddah secondary schools to students' academic achievement. Academic Journals, Vol. 11(7), 328-338. doi.org/10.5897/err2015.2607

Anderson, J. (2017) State policies to overcome the achievement gap and poverty. Education Commission for the States, The Source. Spring, 2017. Retrieved from: http://www.advanc-ed.org/source/state-policies-overcome-achievement-gapand-poverty

Argyris, C. (1958). The organization: What makes it healthy? Harvard business Review, 36(6) 107-116.

Baker, B. D., Farrie, D. and Sciarra, D. G. (2016), Mind the gap: 20 years of progress and retrenchment in school funding and achievement gaps. ETS Research Report Series, 2016, 1-37. doi:10.1002/ets2.12098. doi.org/10.1002/ets2.12098

Barth, R. S. (2002). The culture builder. Educational Leadership. Vol 59, No. 8, pp 6-11, May 2002.

Retrieved from: https://files.eric.ed.gov/fulltext/ED518986.pdf

Blank, R. K. (2011). Closing the achievement gap for economically disadvantaged Students? Analyzing change since No Child Left Behind Using State Assessments and the National Assessment of Educational Progress, Washington, 
DC: Council of Chief State School Officers. Retrieved from: https://files.eric.ed.gov/fulltext/ED518986.pdf

Brosnahan, C. (2011). The impact of a school's organizational health on student achievement: A doctoral thesis for the degree doctor of education, University of Houston. Retrieved from: https://uh-ir.tdl.org/uhir/bitstream/handle/10657/445/BROSNAHAN-DISSERTATION2011.pdf?sequence $=1$

Council of Chief State School Officers CCSSO (2011). Closing the achievement gap for economically disadvantaged students? Analyzing change since No Child Left Behind using state assessments and the National Assessment of Educational Progress, Washington, DC: Council of Chief State School Officers.

Dufour, R. \& Eaker R. (1998). Professional learning communities: Communities that work best practices for enhancing student achievement. Bloomington, IN: Solution Tree Press.

Dufour, R. \& Eaker R. (1998) Professional Learning communities at work: Best Practices for enhancing student achievement. Bloomington, IN: National Education Service. doi.org/10.1093/ajcp/111.4/563

Fairman M., Holmes Morris L. Jr., Hardage, J. \& Lucas, C.S. (1979). Manual for the organization health instrument. Organizational Health. Fayetteville, AK: Diagnostic and Development Corporation.

Fairman, M. \& McLean, L. (2011). Enhancing leadership effectiveness: Theory and practices for sustained systemic success. North Little Rock, AK: Paradigm Media Publishing.

Fairman, M. (2014). Organizational health individualized report. Lenexa, KS: Organizational Health, Diagnostic and Development Corporation.

Goddard, R. D. , Sweetland, S.R. \& Hoy, W.K. (2000, Dec.). Academic emphasis of urban elementary schools and student achievement in reading and mathematics: A multilevel analysis, Educational Administration Quarterly, 36(5), 683-702. doi.org/10.1177/00131610021969173

Hemphill, F.C. \& Vanneman, A. (2011). Achievement gaps: How Hispanic and white students in public schools perform in mathematics and reading on the national assessment of educational progress (NCES 2011-459). Washington, DC: National Center for Education Statistics, Institute of Education Sciences, U.S. Department of Education. doi.org/10.1037/e595292011-001

Hersey P., \& Blanchard, K.H. (1988). Management of Organization behavior: Utilizing Human Resources, Englewood Cliffs, NJ: Prentice-Hall. doi.org/10.2307/2521543

Hoy, W. K. (1990, August). Organizational climate, school health, and effectiveness: A comparative analysis, Educational Administration Quarterly, 26(3), 260 - 27. doi.org/10.1177/0013161X90026003004

Hoy, W. K. (1997, August 1). Middle school climate: An empirical assessment of organizational health and student achievement. Educational Administration Quarterly, 33(3), 290-311 Retrieved from http://dx.doi.org/10.1177/0013161X97033003003

Hoy, W. K. (2012). School characteristics that make a difference for the achievement of all students. Journal of Educational Administration, 50(1), 76-97. doi.org/10.1108/09578231211196078

Johnstone, W. G. (1988). Organizational health instrument technical manual. Little, AK: Organizational Health: Diagnostic and Development Corporation.

MacNeil, A. J., Prater, D.L., \& Busch, S. (2009). The effects of school culture and climate on student achievement. Instructional Journal in Education, January-March, 12(1), 73-84. doi.org/10.1080/13603120701576241 
Miles, M. (1965). Planned change and organizational change: Figure and ground. In R. O. Carlson, Change Processes in the Public Schools (pp. 11-34). Eugene, OR: University of Oregon Press. Retrieved from http:/ / files.eric.ed.gov/fulltext/ED014123.pdf

Murphy, J. (2009). Closing achievement gaps: Lessons learned from the last 15 years. The Phi Delta Kappan, 91 (3), 8-12. doi.org/10.1177/003172170909100303

No Child Left Behind Act of 2001, P.L. 107-110, 107th Congress, Title I - Improving the Academic Achievement of the Disadvantaged, 20 U.S.C. § 1001 Statement of Purpose (3), (January 8, 2002).

Phillips, D. K. \& Clancy, K.T. (1972). Some effects of "social desirability" in survey studies, American Journal of Sociology, 77(5), 921-940. doi.org/10.1086/225231

Reardon, S. F. (May 2013). The widening income achievement gap. Educational Leadership, 70(8), 10-16. Retrieved from: http://www.ascd.org/publications/educationalleadership/may13/vol70/num08/The-Widening-Income-AchievementGap.aspx

Roney, K. \&. (2011). Relationship between organizational health of middle schools and student achievement in reading and math: What middle grades principals should hear. National Forum of Educational Administration and Supervision Journal, 28(4), 1-27.

Sarason, S. (1996). Revisiting "The culture of the school and the problem of change" New York, NY: Teachers College Press. doi.org/10.1177/0192636507310161

Texas Education Agency (2014). Texas academic performance report, Retrieved from: http://ritter.tea.state.tx.us/perfreport/tapr/2014/state.pdf

Thernstrom, S. (2003). No excuses: Closing the racial gap in learning. New York, NY: Simon \& Schuster. doi.org/10.1086/424723

U.S. Department of Education (2002). No Child Left Behind: A Desktop Reference. Washington, DC: Office of Elementary and Secondary Education doi.org/10.1037/e549202006-001

United States Department of Education (2015). Every Student Succeeds Act, Fact Sheet for Final Regulations: Title I, Parts A and Parts B, Assessments under Title I, Part A \& Title I, Part B: Summary of Final Regulations Retrieved from: https://www2.ed.gov/policy/elsec/leg/essa/essaassessmentfactsheet1207.pdf 